\title{
Investigation of Mg-Li-Ca alloys using a Wavelength Dispersive Soft X-ray Emission Spectrometer and EPMA
}

\author{
H. Takahashi ${ }^{1}$, M. Takakura ${ }^{2}$, T. Murano ${ }^{2}$, M. Terauchi $^{3}$, M. Yamasaki ${ }^{4}$, Y. Kawamura $^{4}$, P. McSwiggen $^{5}$ \\ 1. Global business promotion division, JEOLLtd., 13F, Otemachi Nomura Bld. 2-1-1 Otemachi, Chiyoda-ku, Tokyo, \\ 100-0004 Japan \\ 2. SM business unit JEOLLtd., 1-2Musashino, 3-chome, Akishima, Tokyo 196-8558, Japan. \\ 3. Institute for Multidisciplinary Research for Advanced Materials, Tohoku University, Sendai 980-8577, Japan. \\ 4. Magnesium Research Center, Kumamoto University, 39-1, 2-chome, Kurokami, Chou-ku, Kumamoto, 860-8555, Japan. \\ 5. JEOLUSA, 11 Dearbom Rd. Peabody, MA 01960, USA.
}

A new group of ultra-lightweight magnesium-lithium-calcium alloys have recently been developed. These innovative alloys have some superior characteristic including high specific strength. These unique, and long sought after features, will soon lead to the use of these alloys in personal computers, aircraft, trains, automobiles, and many other manufactured products. However, the microanalysis of these alloys is significantly more challenging due to the presence of lithium. The presence of lithium limits the available analytical techniques to either that of using ultra, low-energy X-rays, or a surface analysis technique. A new method for analyzing the ultra low-energy X-rays was applied to these challenging alloys.

We chose to analyze the lithium and magnesium using the $\mathrm{Li}-\mathrm{K}$ and $\mathrm{Mg}-\mathrm{L}$ X-ray emission using a newly developed wavelength dispersive, soft X-ray emission spectrometer (WD-SXES) attached to an electron probe microanalyzer (JEOL EPMA JXA-8230)[1-3]. The sample investigated is in the ternary $\mathrm{Mg}-\mathrm{Li}-\mathrm{Ca}$ system. Sample preparation involved using an ion cross-section polisher (CP) to both polish and flatten the oxidized surface. The WD-SXES was tuned the lower limit to allow for the detection of the $\mathrm{Mg}-\mathrm{L}$ emission at between 50 to $45 \mathrm{eV}$. Spectrum element mapping was acquired using the lower energy $\mathrm{Mg} \mathrm{L}, \mathrm{Li}-\mathrm{K}$ and $\mathrm{Ca}-\mathrm{Ll}$ emissions. These elemental maps and the backscattered electron image are shown in Figure 1, and spectra from the precipitates and matrix are compared in Figure 2. The element mapping shows that the $\mathrm{Mg}$ and $\mathrm{Li}$ are in a higher abundance in the darker phase (BEI) than in the lighter phase. The spectra data provide additional insights into their structure. The sharp leading edge of the $\mathrm{Mg}-\mathrm{L}$ emission line at $50 \mathrm{eV}$ corresponds to the Fermi-edge, and its unique lower energy profile corresponds to the electron density of state due to the brillouin zone [4]. Therefore different peak shapes must correspond to structural states of the two phases. The Li-K emission is also clearly detected and can be seen to have a higher concentration in the precipitate than in the matrix.

Using the WD-SXES to investigate these alloys clearly shows that this method of spectrum map is useful in distinguishing both the chemical bonding states and the distribution of magnesium and lithium between the phases.

\section{Reference}

[1] M. Terauchi, et al., J. Electron Microscopy, 61, 1 (2012).

[2] T. Imazono, et al., Appl. Opt. 51, 2351 (2012).

[3] H. Takahashi, et al., Microscopy and Microanalysis, 19 (supple. 2), 1258 (2013).

[4] D. J. Fabian "Soft X-ray band and electric structure" 62, (1968) Acade. Press. 


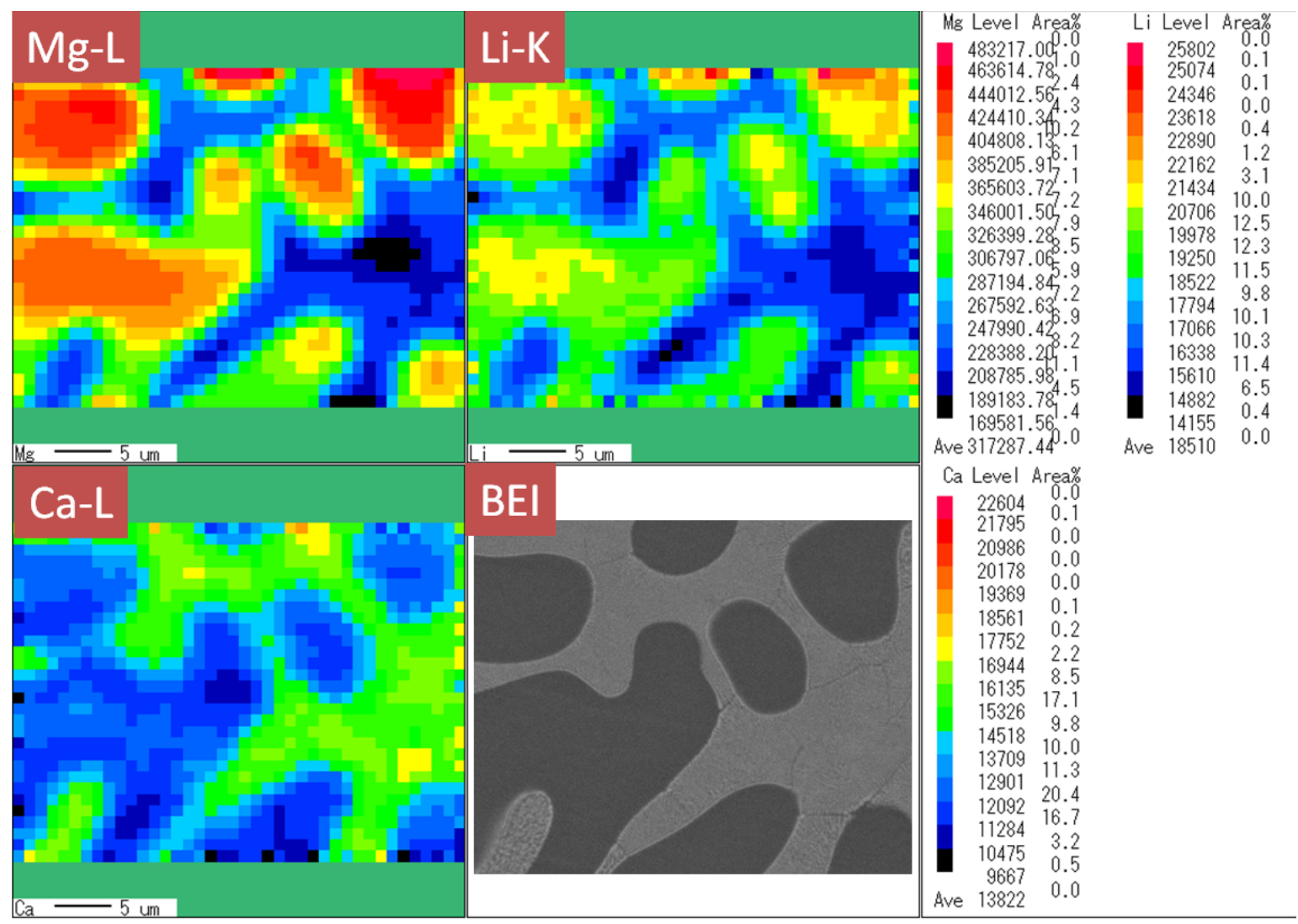

Figure 1. Elemental distribution of $\mathrm{Mg}, \mathrm{Li}$, and $\mathrm{Ca}$ and backscattered electron image using WD-SXESEPMA JXA-8230.
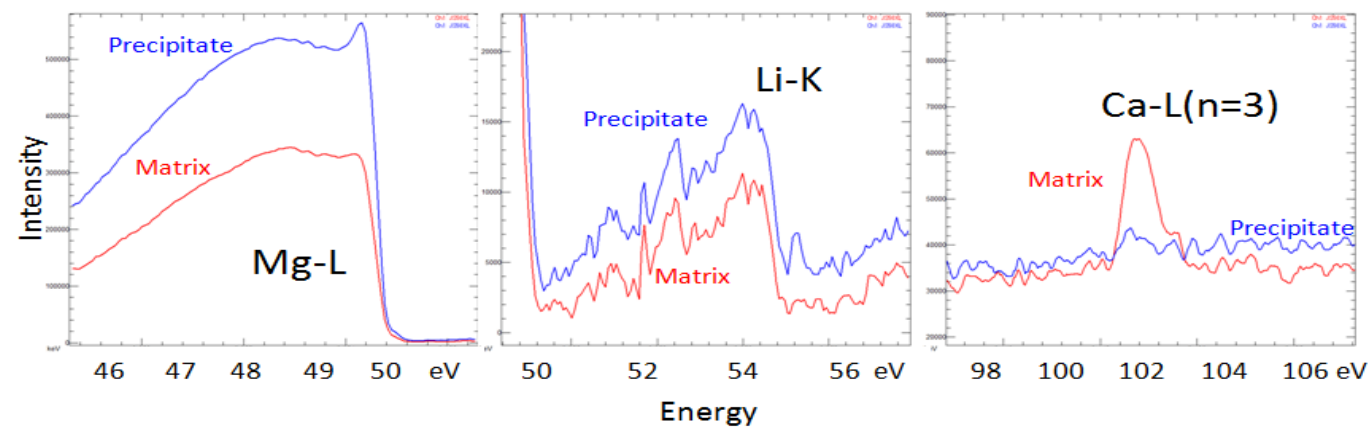

Figure 2. Comparison of $\mathrm{Mg}-\mathrm{L}, \mathrm{Li}-\mathrm{K}$ and $\mathrm{Ca}-\mathrm{L} \mathrm{l}(\mathrm{n}=3)$ spectra from the two phases in the $\mathrm{Mg}-\mathrm{Li}-\mathrm{Ca}$ alloy. Red solid line - Matrix; blue solid line - Precipitate. 